\title{
Development of Pyrazolopyrimidine Anti-Wolbachia Agents for the Treatment of Filariasis
}

Paul McGillan, Neil G. Berry, Gemma L. Nixon, Suet C. Leung, Peter J. H. Webborn, Mark C. Wenlock, Stefan Kavanagh, Andrew Cassidy, Rachel H. Clare, Darren A. Cook, Kelly L. Johnston, Louise Ford, Stephen A. Ward, Mark J. Taylor, W. David Hong,* and Paul M. O’Neill*

Cite This: ACS Med. Chem. Lett. 2021, 12, 1421-1426

Read Online

ACCESS | Llll Metrics \& More | 回 Article Recommendations | St Supporting Information

ABSTRACT: Anti-Wolbachia therapy has been identified as a viable treatment for combating filarial diseases. Phenotypic screening revealed a series of pyrazolopyrimidine hits with potent anti-Wolbachia activity. This paper focuses on the exploration of the SAR for this chemotype, with improvement of metabolic stability and solubility profiles using medicinal chemistry approaches. Organic synthesis has enabled functionalization of the pyrazolopyrimidine core at multiple positions, generating a library of compounds of which many analogues possess nanomolar activity against Wolbachia in vitro with improved DMPK parameters. A lead compound, 15f, was selected for in vivo

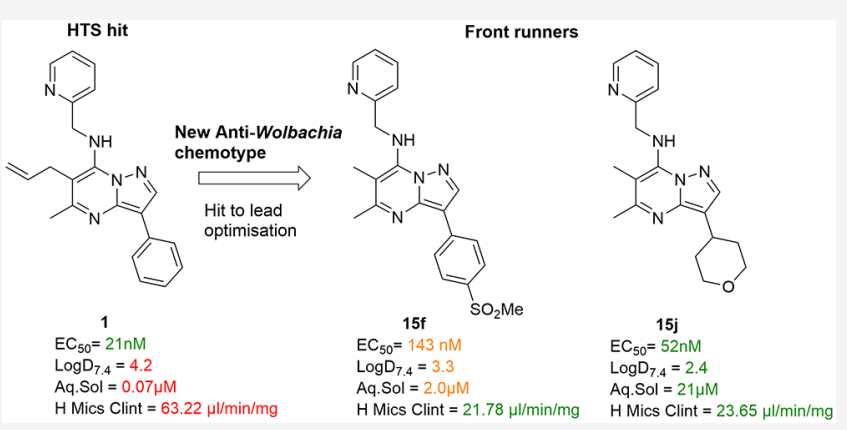
pharmacokinetics (PK) profiling in mice. The combination of potent anti-Wolbachia activity in two in vitro assessments plus the exceptional oral PK profiles in mice puts this lead compound in a strong position for in vivo proof-of-concept pharmacodynamics studies and demonstrates the strong potential for further optimization and development of this series for treatment of filariasis in the future.

KEYWORDS: Wolbachia, Pyrazolopyrimidine, Onchocerciasis, Filariasis

$\mathrm{F}$ ilarial nematodes are the causative pathogens of the neglected tropical diseases lymphatic filariasis (LF) and onchocerciasis that affect tens of millions people throughout the tropics and contribute to serious public health and socioeconomic problems. Onchocerciasis (the cause of river blindness) is the second leading infectious cause of blindness. These diseases combined are one of the leading causes of morbidity worldwide. The main causative agents for these conditions are the nematodes Onchocerca volvulus (onchocerciasis), Wuchereria bancrofti, Brugia malayi, and Brugia timori (LF). ${ }^{1}$ The latest recommended treatment for LF in areas which are not coendemic for onchocerciasis or other filarial disease, loiasis, is a triple combination of ivermectin, diethylcarbamazine plus albendazole. ${ }^{2}$ Ivermectin is the recommended treatment for onchocerciasis; however, it cannot be used in areas co-endemic for loiasis due to potentially fatal adverse effects. These direct acting antifilarial drugs primarily target microfilariae, the immature worm stage, and thus can prevent transmission, but they have little macrofilaricidal activity against the adult worms. Hence, these drugs require lengthy treatments that can be as long as 15 years. ${ }^{3,4}$ The association of current direct acting antifilarial agents with undesired adverse effects, contraindicated patient groups combined with a growing concern of resistance development, is driving current research efforts to identify and generate safe therapeutic alternatives. ${ }^{5,6}$

The nematodes which are responsible for causing these two filarial diseases share an essential endosymbiotic relationship with the bacterium Wolbachia. ${ }^{7,8}$ Although the exact nature of this relationship is not yet fully understood, anti-Wolbachia therapy has been proven clinically by an existing antibiotic, doxycycline, which delivers safe macrofilaricidal activity with superior therapeutic outcomes compared to current antifilarial drugs. $^{9-11}$

Pyrazolopyrimidine compounds have frequently appeared in the literature with a variety of different pharmacological activities such as kinase inhibitors, ${ }^{12,13}$ antituberculosis, ${ }^{14}$ antimalarial $^{15}$ and antiviral ${ }^{16}$ agents, and antidepressants. ${ }^{17}$ The original hit for this chemotype (1) which resulted from a phenotypic high-throughput screen (HTS) of a divergent chemical library donated by the Medicines for Malaria Venture

Received: April 15, 2021

Accepted: August 16, 2021

Published: August 20, 2021 
(MMV) is displayed in Figure 1 with measured in vitro activity $\left(\mathrm{EC}_{50}\right)$ against Wolbachia (wAlbB) infected insect cells (Aedes

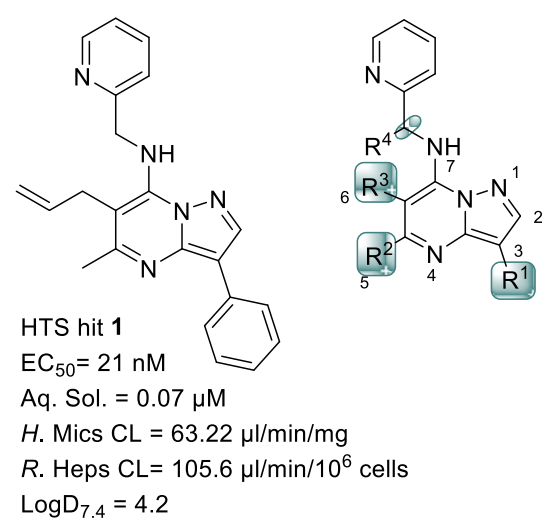

Figure 1. Structure of the HTS hit $\mathbf{1}$ and the pyrazolopyrimidine scaffold with the areas for SAR studies highlighted.

albopictus, C6/36) and drug metabolism/pharmacokinetic (DMPK) properties. According to the HTS data of other close pyrazolopyrimidine analogues screened in the same campaign (data not shown), some preliminary indication of structure-activity relationship (SAR) was observed and the areas of focus for SAR studies and optimization are highlighted in Figure 1. The aim of the work described here was to develop pyrazolopyrimidine leads with potent anti-Wolbachia activity and desired DMPK properties that could be further developed as oral drugs for the treatment of filariasis.

The cascade depicted in Figure 2 was followed for the optimization of the compounds described in this work. In vitro anti-Wolbachia potency was assessed in parallel with in vitro

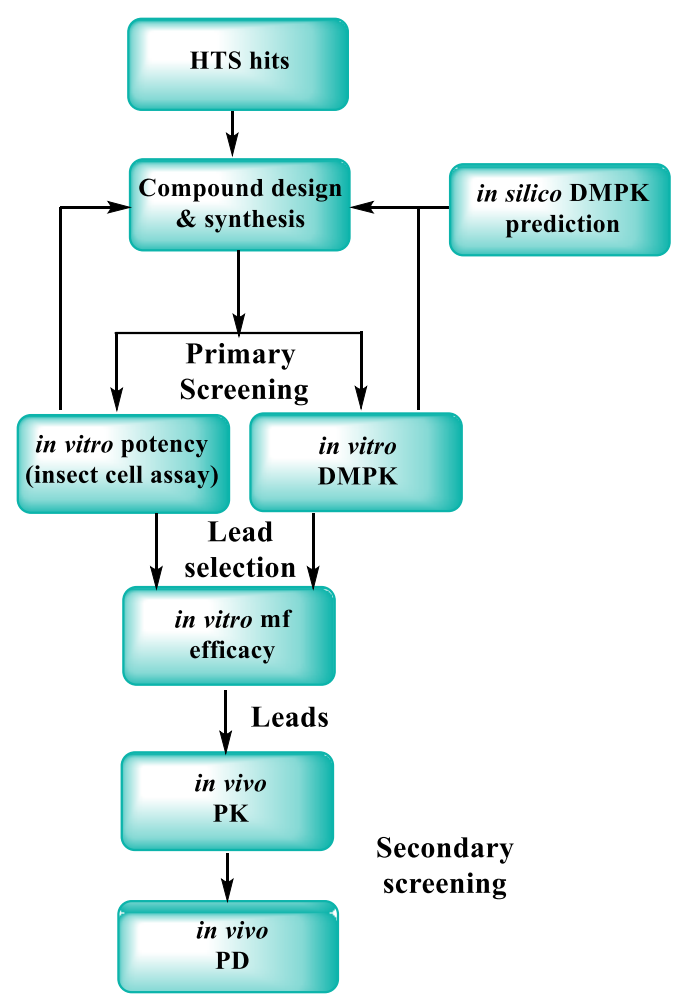

Figure 2. Screening cascade for the design, synthesis and testing of anti-Wolbachia compounds.
DMPK screening. ${ }^{18}$ Compounds showing a good balance of potency and metabolic stability were then selected to test their anti-Wolbachia activity against Brugia malayi microfilariae (mf) in vitro and for in vivo PK profiling in mice. This secondary in vitro assay was developed to provide a link between the in vitro insect cell-based assay and the in vivo B. malayi SCID mouse model. Although the throughput of the $\mathrm{mf}$ assay is limited due to the availability of the $B$. malayi $\mathrm{mf}$, it enables the assessment of the anti-Wolbachia activity in one of the targeted human parasites, providing important evidence of translation between different species of Wolbachia and hosts. Finally, front runners identified from the two above tests would be selected for the in vivo PD study where SCID mice are infected with the human parasite B. malayi. ${ }^{19}$

Despite the high potency $\left(\mathrm{EC}_{50}=21 \mathrm{nM}\right)$ of the original hit 1, DMPK assessments highlighted poor metabolic stability and low aqueous solubility. (Figure 1) The phenyl ring, allyl substitution, and methylene linker were some of the positions within the hit molecule that were predicted to be susceptible to oxidative CYP metabolism. Hence, the early hit to lead optimization was focused on enhancing the metabolic stability while maintaining potency.

The initial synthetic route (Scheme 1) was developed to allow for the synthesis of analogues with modifications at the

\section{Scheme 1. Synthetic Route for Analogues in the} Pyrazolopyrimidine Template

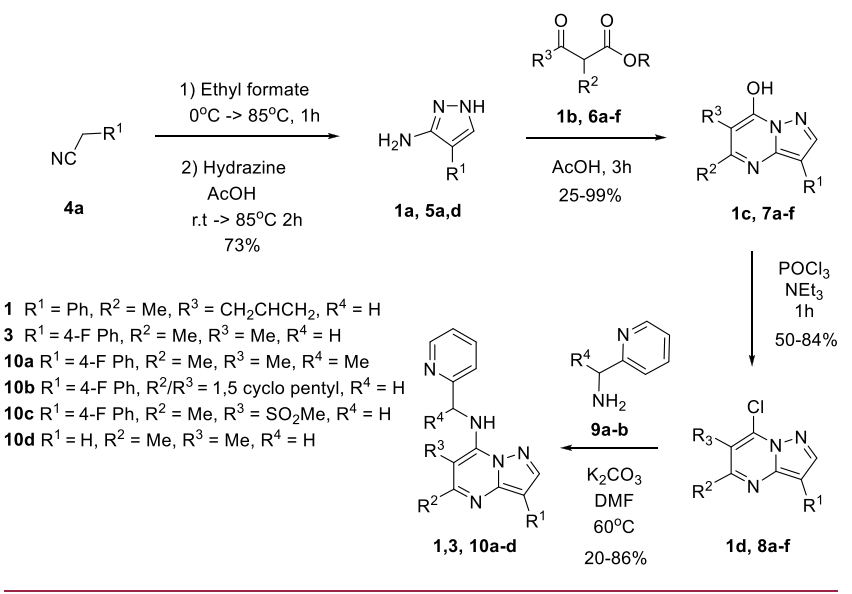

$\mathrm{R}^{2}$-, $\mathrm{R}^{3}$-, and 7-positions of the pyrazolopyrimidine ring. While many necessary 5-amino pyrazoles (1a, 5d, $\mathrm{R}^{1}=\mathrm{Ph}, \mathrm{H}$ respectively) are commercially available, it was also possible to synthesize them in a two-step reaction from the corresponding nitrile $\left(4 \mathrm{a}, \mathrm{R}^{1}=4-\mathrm{F}-\mathrm{Ph}\right)$ using base (NaOEt or LDA) and ethyl formate followed by hydrazine mediated cyclization. This was followed by an acid-catalyzed pyrimidine ring formation using the pyrazoles $\mathbf{1 a}, \mathbf{5} \mathbf{a}, \mathbf{d}$ and $\beta$-keto esters $\mathbf{1 b}, \mathbf{6} \mathbf{a}-\mathbf{f}^{20}$

When the 5-position of the pyrazolopyrimidine is unsubstituted $\left(\mathrm{R}^{2}=\mathrm{H}\right)$, acid catalyzed cyclization is not suitable for the initial imine formation step. For these analogues, the pyrimidine ring was formed by reaction of the appropriate pyrazole and aldehyde to give the imine intermediate which cyclizes upon addition of $\mathrm{KO}^{t} \mathrm{Bu}$. Chlorination of the 7hydroxy pyrimidine intermediates $\mathbf{1 c}, 7 \mathbf{a}-\mathbf{f}$ was achieved using phosphoryl chloride and subsequent substitution of intermediates $\mathbf{1 d}, \mathbf{8 a}-\mathbf{f}$ was achieved by aromatic substitution with the appropriate amines, $9 \mathbf{a}, \mathbf{b}$, to produce the pyrazolopyrimidines, 1,3 , and $10 a-d$. 
While it is possible to use the appropriate nitriles as starting material for the synthesis of target compounds with different groups at the $\mathrm{R}^{1}$-position, a divergent orientated synthesis at this position was desirable for the production of a number of target analogues from a common intermediate. (Scheme 2)

Scheme 2. Optimized Route for the Synthesis of Analogues with Modified 3-Positions ${ }^{a}$

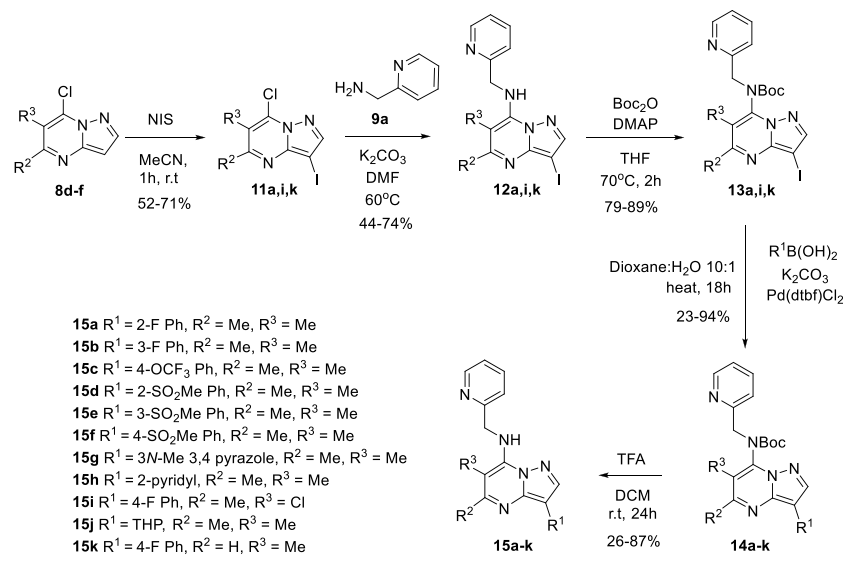

${ }^{a}$ Note: THP $=$ Tetrahydropyran.

Functionalization at the $\mathrm{R}^{1}$-position can also be achieved via iodination of the pyrazolopyrimidines $8 \mathbf{d}-\mathbf{f}\left(\mathrm{R}^{1}=\mathrm{H}\right)$ using $N$ iodosuccinimide (NIS). ${ }^{2}$ This pathway requires Boc-protection of the free amines 12 to allow for Suzuki-mediated coupling of intermediates 13 with the corresponding boronic acid. Finally TFA-mediated Boc-deprotection of compounds $14 \mathbf{a}-\mathbf{k}$ afforded the desired targets $15 \mathbf{a}-\mathbf{k}$, which contained a variety of monosubstituted phenyl rings and nitrogen heterocycles.

Substitutions at the $\mathbf{R}^{3}$-Position. Replacement of the allyl group at this position in the original hit $\mathbf{1}$ with a methyl substituent resulted in excellent potency (compound 2, Table $1, \mathrm{EC}_{50}=19 \mathrm{nM}$ ) and improved metabolic stability as shown by rat hepatocyte clearance of compound 2 (Table 2 ). The analogue with ring-fusion of a lipophilic cyclopentyl ring at $\mathrm{R}^{2}$ and $\mathrm{R}^{3}$ (10b) showed good anti-Wolbachia activity $\left(\mathrm{EC}_{50}=79\right.$ $\mathrm{nM}$ ) and demonstrated that modifications at both positions could be tolerated. This modification did not improve aqueous solubility, but the cyclopentyl ring connecting these two positions increased metabolic stability. Chlorine was also tolerated at the $\mathrm{R}^{3}$-position in terms of potency and has a positive effect on metabolic stability in comparison to the corresponding 6-methyl analogues (15i vs 3 ). On the other hand, $\mathrm{SO}_{2} \mathrm{Me}$ group at the $\mathrm{R}^{3}$-position $(10 \mathrm{c})$ reduced antiWolbachia activity noticeably.

Substitutions at the $\mathbf{R}^{\mathbf{4}}$-Position. In an effort to reduce the potential metabolism of the methylene linker, an analogue with a methyl substitution at this position (10a) was investigated. Methylation of the linker imparts a 2-fold increase in human microsomal stability, but this modification leads to a 4-fold loss in activity (compounds 10a vs 3 ). According to HTS results (data not shown here), we found that the SAR was restricted at the 2 -pyridyl side-chain. Any minor modifications to this ring significantly reduced compound potency. For this reason, we focused more on the $\mathrm{R}^{1}$-position of the pyrazolopyrimidine core since the HTS data suggested that a wider range of modifications might be tolerated at this position.
Table 1. In Vitro Potency Data of Key Analogues

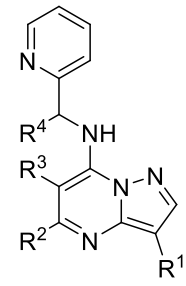

\begin{tabular}{|c|c|c|c|c|c|}
\hline & $\mathbf{R}^{1}$ & $\mathbf{R}^{2}$ & $\mathbf{R}^{3}$ & $\mathbf{R}^{4}$ & $\begin{array}{l}\text { Anti- } \\
\text { Wolbachia } \\
\mathrm{EC}_{50}(\mathrm{nM})^{a}\end{array}$ \\
\hline 1 & $\mathrm{Ph}$ & $\mathrm{Me}$ & $\mathrm{CH}_{2} \mathrm{CH}=\mathrm{CH}_{2}$ & $\mathrm{H}$ & 21 \\
\hline 2 & $\mathrm{Ph}$ & $\mathrm{Me}$ & $\mathrm{Me}$ & $\mathrm{H}$ & 19 \\
\hline 3 & 4-F Ph & $\mathrm{Me}$ & $\mathrm{Me}$ & $\mathrm{H}$ & 17 \\
\hline $10 \mathrm{a}$ & 4-F Ph & $\mathrm{Me}$ & $\mathrm{Me}$ & $\mathrm{Me}$ & 93 \\
\hline $10 \mathrm{~b}$ & 4-F Ph & $\begin{array}{l}1- \\
\text { cycl } \\
\text { ope } \\
\text { ntyl }\end{array}$ & 5-cyclopentyl & $\mathrm{H}$ & 79 \\
\hline 10c & 4-F Ph & $\mathrm{Me}$ & $\mathrm{SO}_{2} \mathrm{Me}$ & $\mathrm{H}$ & 704 \\
\hline 10d & $\mathrm{H}$ & $\mathrm{Me}$ & $\mathrm{Me}$ & $\mathrm{H}$ & 105 \\
\hline $15 \mathrm{a}$ & 2-F Ph & $\mathrm{Me}$ & $\mathrm{Me}$ & $\mathrm{H}$ & 11 \\
\hline $15 \mathrm{~b}$ & 3-F Ph & $\mathrm{Me}$ & $\mathrm{Me}$ & $\mathrm{H}$ & 1000 \\
\hline $15 \mathrm{c}$ & $4-\mathrm{OCF}_{3} \mathrm{Ph}$ & $\mathrm{Me}$ & $\mathrm{Me}$ & $\mathrm{H}$ & 664 \\
\hline$\overline{15 d}$ & $2-\mathrm{SO}_{2} \mathrm{Me} \mathrm{Ph}$ & $\mathrm{Me}$ & $\mathrm{Me}$ & $\mathrm{H}$ & $>2500$ \\
\hline $15 \mathrm{e}$ & $3-\mathrm{SO}_{2} \mathrm{Me} \mathrm{Ph}$ & $\mathrm{Me}$ & $\mathrm{Me}$ & $\mathrm{H}$ & $>2500$ \\
\hline $15 \mathrm{f}$ & $4-\mathrm{SO}_{2} \mathrm{Me} \mathrm{Ph}$ & $\mathrm{Me}$ & $\mathrm{Me}$ & $\mathrm{H}$ & 143 \\
\hline $15 \mathrm{~g}$ & $a_{N}$ & $\mathrm{Me}$ & $\mathrm{Me}$ & $\mathrm{H}$ & 119 \\
\hline $15 \mathrm{~h}$ & 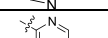 & $\mathrm{Me}$ & $\mathrm{Me}$ & $\mathrm{H}$ & 43 \\
\hline $15 \mathrm{i}$ & 4-F Ph & $\mathrm{Me}$ & $\mathrm{Cl}$ & $\mathrm{H}$ & 51 \\
\hline $15 j$ & $-3 \sqrt{0}$ & $\mathrm{Me}$ & $\mathrm{Me}$ & $\mathrm{H}$ & 52 \\
\hline $15 \mathrm{k}$ & 4-F Ph & $\mathrm{H}$ & $\mathrm{Me}$ & $\mathrm{H}$ & 38 \\
\hline
\end{tabular}

${ }^{a}$ Note: All tested compounds showed no cytotoxicity against the insect cells at the top concentration $(5 \mu \mathrm{M})$ in the assay.

Table 2. In Vitro DMPK Data of Pyrazolopyrimidine Analogues $^{a}$

\begin{tabular}{|c|c|c|c|c|c|}
\hline & $\log D_{7.4}$ & $\begin{array}{l}\text { Aq. Sol. } \\
(\mu \mathrm{M})\end{array}$ & $\begin{array}{l}\text { H. Mics. CL. } \\
(\mu \mathrm{L} / \mathrm{min} / \mathrm{mg})\end{array}$ & $\begin{array}{c}\text { R. Hep. CL } \\
\left(\mu \mathrm{L} / \mathrm{min} / 10^{6} \text { cells }\right)\end{array}$ & $\begin{array}{l}\text { H. } \\
\text { PPB } \\
(\%)\end{array}$ \\
\hline 1 & 4.2 & 0.07 & 63.22 & 105.60 & 99.9 \\
\hline 2 & 4.0 & 0.40 & ND & 59.03 & 99.80 \\
\hline 3 & 4.3 & 0.90 & 49.19 & 67.66 & 99.8 \\
\hline $10 \mathrm{a}$ & 4.3 & 0.30 & 24.49 & 75.43 & ND \\
\hline $10 b$ & 3.3 & 0.50 & 48.86 & 41.25 & 99.0 \\
\hline $10 \mathrm{c}$ & 3.7 & 0.01 & 8.76 & 46.48 & 99.7 \\
\hline $10 d$ & 2.0 & 561 & 261.80 & 109.60 & 77.0 \\
\hline $15 a$ & 4.0 & 0.60 & 83.97 & 113.20 & 99.9 \\
\hline $15 b$ & 4.1 & 1.00 & 59.33 & 86.16 & 99.9 \\
\hline $15 \mathrm{c}$ & 4.5 & 5.00 & 8.76 & 156.60 & 97.9 \\
\hline $15 d$ & 2.3 & 11.0 & 74.15 & $>300.00$ & 88.0 \\
\hline $15 \mathrm{e}$ & 3.0 & 2.00 & 12.08 & 147.80 & 96.6 \\
\hline $15 f$ & 3.3 & 2.00 & 21.78 & 27.58 & 99.8 \\
\hline $15 \mathrm{~g}$ & 2.7 & 43.0 & 44.83 & 10.31 & 91.8 \\
\hline $15 \mathrm{~h}$ & 2.3 & 30.0 & 243.60 & 144.90 & 97.4 \\
\hline $15 \mathrm{i}$ & 4.3 & 2.0 & 44.62 & 26.37 & 99.5 \\
\hline $15 j$ & 2.4 & 21.0 & 23.65 & 71.84 & ND \\
\hline $15 k$ & 4.0 & 6.0 & 37.48 & 45.53 & 99.6 \\
\hline
\end{tabular}

${ }^{a}$ Notes: Aq. Sol. $=$ aqueous solubility in pH7.4 PBS; H. Mics. CL $=$ intrinsic human microsomal clearance measured in vitro; R. Hep. CL $=$ intrinsic Rat hepatocyte clearance measured in vitro; $\mathrm{ND}=$ not determined.

Substitutions at the $\mathbf{R}^{1}$-Position. The $\mathrm{R}^{1}$-aryl side chain is not essential for anti-Wolbachia activity; however, removal of 
the aromatic ring resulted in some reduction in potency $(10 \mathrm{~d}$ $\mathrm{EC}_{50}=105 \mathrm{nM}$ ) coupled with a significant increase in aqueous solubility. A range of small substitutions at the para-position of the phenyl ring are generally tolerated, while a 4-fluoro substitution (3) appears to be optimal for activity $\left(\mathrm{EC}_{50}=17\right.$ $\mathrm{nM}$ ). Substitution of the polar $\mathrm{SO}_{2} \mathrm{Me}$ group at the paraposition (15f) resulted in reducing $\log \mathrm{D}$, increasing aqueous solubility and improving metabolic stability. However, similar substitution with the $\mathrm{SO}_{2} \mathrm{Me}$ group at the ortho- and metapositions of the phenyl ring is not tolerated, as shown by compounds $15 \mathrm{~d}$ and $15 \mathrm{e}$, where substitution results in a significant reduction in potency. On the other hand, smaller substituents, such as fluorine are tolerated in the ortho-position although these small substitutions offered no significant improvements to DMPK properties. While compound 3 displayed improved in vitro metabolic stability comparing with HTS hit 1, it still suffered from poor aqueous solubility.

In an attempt to reduce $\log \mathrm{D}$ further and to improve aqueous solubility, analogues $15 \mathrm{~g}$ and $15 \mathrm{~h}$ containing the heterocyclic aromatic 1-methyl-1H-pyrazolyl and 2-pyridyl groups were synthesized as more polar/LogD reducing phenyl ring replacements. These modifications both greatly enhanced the aqueous solubility and $\operatorname{lowered} \log \mathrm{D}$ with the 2-pyridyl analogue $15 \mathrm{~h}$ maintaining the majority of its potency.

Compound $15 \mathrm{~g}$ proved to be reasonably stable metabolically; however, a near 10 -fold drop in activity supported further investigation into other areas of the scaffold to improve overall properties. Exploration of saturated heterocyclic ring systems led to the synthesis of compound $\mathbf{1 5 j}$ containing the tetrahydropyran (THP) moiety. The THP side-chain is well tolerated for potency $\left(\mathrm{EC}_{50}=52 \mathrm{nM}\right)$ while improving DMPK properties comparing with HTS hit 1 .

Substitutions at the $\mathbf{R}^{2}$-Position. Substitution at this position is not essential for anti-Wolbachia activity. It was demonstrated that the removal of the methyl substituent from the $\mathrm{R}^{2}$-position (15k) was tolerated in terms of potency and resulted in some improvement in DMPK properties when compared to compound 3 . This result suggests the $\mathrm{R}^{2}$-position was another area that could be further explored for optimization of potency and DMPK in future work.

Anti-Wolbachia Activity Assessment in B. malayi mf Assay. The $\mathrm{mf}$ assay is an orthogonal in vitro assay that uses $B$. malayi microfilariae to confirm the anti-Wolbachia activity of tested compounds against the human parasitic nematode. ${ }^{21,22}$ After being screened for potency and DMPK properties in vitro, a number of selected analogues were tested at $5 \mu \mathrm{M}$ alongside the gold-standard doxycycline for comparison of anti-Wolbachia activity in the $\mathrm{mf}$ assay. The majority of tested compounds demonstrated good activity, comparable to doxycycline, in this assay except for 15i (Table 3). The secondary readout of the $\mathrm{mf}$ assay is the motility of the $\mathrm{mf}$ by the tested compounds comparing with vehicle control. For anti-Wolbachia drugs, such as doxycycline, they should not affect the motility of the parasitic worm since this indicates offtarget effects. For this reason, the chloro-substituted analogue 15i was considered unsuitable for further development as an anti-Wolbachia drug as it had significant effects on worm motility in the assay.

In Vivo Pharmacokinetic (PK) Profiling in Mice. Taking all the in vitro results into consideration, compounds $\mathbf{1 5 f}$ and 15j possessed a suitable balance of high potency, good DMPK properties and acceptable preliminary safety profiles (e.g., cytotoxicity and hERG inhibition ${ }^{23}$ ), and $\mathbf{1 5 f}$ was chosen for in
Table 3. In Vitro Potency of Key Analogues in the B. malayi mf Assay

$\begin{array}{ccc}\text { anti-Wolbachia } & \begin{array}{c}\text { anti-Wolbachia potency from mf assay (6 } \\ \text { potency from cell } \\ \text { assay } \mathrm{EC}_{50}(\mathrm{nM})\end{array} & \begin{array}{c}\text { ays at } 5 \mu \mathrm{M} \% \text { Wolbachia reduction in } \\ \text { wsp:gst }\end{array} \\ \text { DOX } & 17 & 86.5 \\ \text { 1 } & 21 & 75.60 \\ \text { 3 } & 17 & 83.20 \\ \text { 10d } & 105 & 77.10 \\ \text { 15f } & 143 & 80.40 \\ \text { 15i } & 51 & \text { toxic }^{b} \\ \text { 15j } & 52 & 85\end{array}$

${ }^{a}$ wsp, Wolbachia surface protein copy number, median $\%$ reduction cf. vehicle (DMSO) control; gst, GST copy number (single copy gene, worm size biomarker). ${ }^{b}$ Significantly reduced motility of the $\mathrm{mf}$ after 6 days incubation comparing with vehicle (DMSO) control.

vivo PK evaluation. Compound $\mathbf{1 5} \mathbf{f}$ was dosed orally to SCID mice at 50 and $100 \mathrm{mg} / \mathrm{kg}$ using a standard suspended vehicle (SSV); results from the study are shown in Chart 1 and Table

Chart 1. Mean Plasma Concentration of Compound $15 \mathrm{f}$ Following Dosing to SCID Mice with SSV

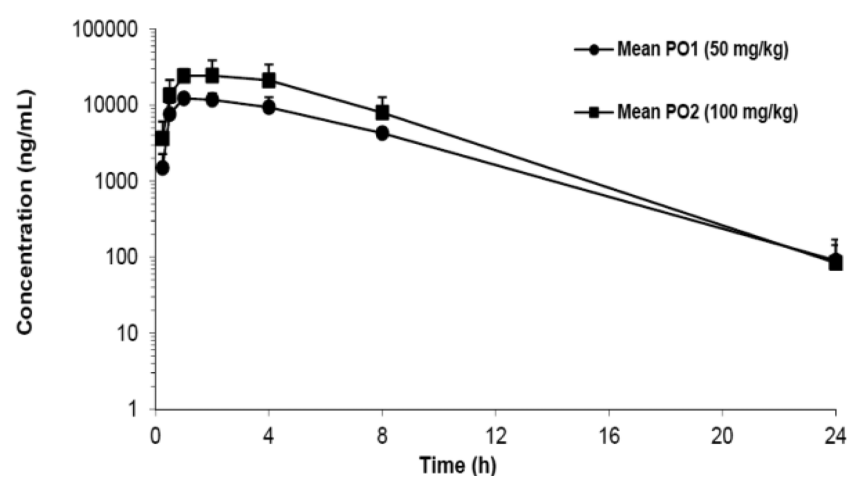

Table 4. In Vivo PK Profile of Compound 15f, Dosing to SCID Mice Using SSV

$\begin{array}{lll}\text { dosage (oral) } & 50 \mathrm{mg} / \mathrm{kg} & 100 \mathrm{mg} / \mathrm{kg} \\ T_{1 / 2}(\mathrm{~h}) & 2.9 & 2.4 \\ C_{\max }(\mu \mathrm{g} / \mathrm{L}) & 13067 & 27800 \\ T_{\max }(\mathrm{h}) & 1.33 & 1.67 \\ \mathrm{AUC}_{0-t}(\mu \mathrm{g} \cdot \mathrm{h} / \mathrm{L}) & 82209 & 162617\end{array}$

4. Despite limited aqueous solubility, this compound demonstrates good tolerability, excellent in vivo PK profiles with high exposure, reasonable half-life and dose-proportional AUC. Based on this data $\mathbf{1 5} \mathbf{f}$ has been selected as a lead for an in vivo proof-of-concept pharmacodynamics study and further optimization.

In summary, the initial potent pyrazolopyrimidine hit 1, which has poor metabolic stability and inadequate aqueous solubility parameters, has been optimized to provide a number of highly potent compounds with enhanced DMPK properties as represented by lead molecules $\mathbf{1 5 f}$ and $\mathbf{1 5 j}$. A summary of the key SAR is highlighted in Figure 3.

More explorations of the $\mathrm{R}^{1}$-position and potential functionalization of the 2-position of the pyrazolopyrimidine core could further improve the anti-Wolbachia potency and the 


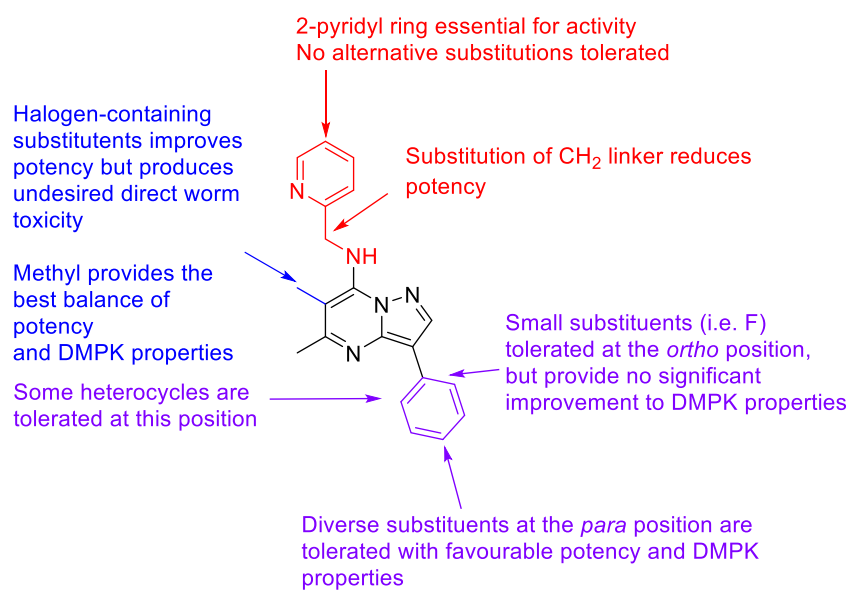

Figure 3. Summary of the SAR of anti-Wolbachia pyrazolopyrimidines.

overall DMPK properties. These future directions will be determined by the results of in vivo efficacy studies of $\mathbf{1 5 f}$ which will be reported in due course. In addition, the in vivo PK and PD studies of the other lead, $\mathbf{1 5 j}$ will be triggered if the proof-of-concept in vivo efficacy study of $\mathbf{1 5 f}$ is positive.

\section{ASSOCIATED CONTENT}

\section{SI Supporting Information}

The Supporting Information is available free of charge at https://pubs.acs.org/doi/10.1021/acsmedchemlett.1c00216.

In vitro biological testing methods, experimental procedure of the synthesis, and characterization of the reported compounds (PDF)

\section{AUTHOR INFORMATION}

\section{Corresponding Authors}

Paul M. O'Neill - Department of Chemistry, University of Liverpool, Liverpool L69 7ZD, United Kingdom; ๑ orcid.org/0000-0003-4338-0317; Email: pmoneill@ liverpool.ac.uk

W. David Hong - Department of Chemistry, University of Liverpool, Liverpool L69 7ZD, United Kingdom; Department of Tropical Disease Biology, Liverpool School of Tropical Medicine, Liverpool L3 5QA, United Kingdom; 이이.org/ 0000-0002-0030-3007; Email: davidhwq@liverpool.ac.uk

\section{Authors}

Paul McGillan - Department of Chemistry, University of Liverpool, Liverpool L69 7ZD, United Kingdom

Neil G. Berry - Department of Chemistry, University of Liverpool, Liverpool L69 7ZD, United Kingdom

Gemma L. Nixon - Department of Chemistry, University of Liverpool, Liverpool L69 7ZD, United Kingdom; (1) orcid.org/0000-0002-9730-0960

Suet C. Leung - Department of Chemistry, University of Liverpool, Liverpool L69 7ZD, United Kingdom

Peter J. H. Webborn - Drug Safety \& Metabolism, IMED Biotech Unit, AstraZeneca U.K., Cambridge CB2 OAA, United Kingdom; Present Address: PJHW Consultancy Ltd., Macclesfield, Cheshire SK11 9HD, United Kingdom

Mark C. Wenlock - Drug Safety \& Metabolism, IMED Biotech Unit, AstraZeneca U.K., Cambridge CB2 OAA, United Kingdom; Present Address: Cyprotex Discovery
Limited, No. 24 Mereside, Alderley Park, Macclesfield, Cheshire SK10 4TG, United Kingdom

Stefan Kavanagh - Oncology Safety Sciences, Clinical Pharmacology \& Safety Sciences, R\&D, AstraZeneca, Cambridge CB2 OAA, United Kingdom

Andrew Cassidy - Department of Tropical Disease Biology, Liverpool School of Tropical Medicine, Liverpool L3 5QA, United Kingdom

Rachel H. Clare - Department of Tropical Disease Biology, Liverpool School of Tropical Medicine, Liverpool L3 5QA, United Kingdom; 이이.org/0000-0002-3945-0530

Darren A. Cook - Department of Tropical Disease Biology, Liverpool School of Tropical Medicine, Liverpool L3 5QA, United Kingdom

Kelly L. Johnston - Department of Tropical Disease Biology, Liverpool School of Tropical Medicine, Liverpool L3 5QA, United Kingdom; Institute of Systems, Molecular \& Integrative Biology, School of Life Sciences, University of Liverpool, Liverpool L69 7ZB, United Kingdom

Louise Ford - Department of Tropical Disease Biology, Liverpool School of Tropical Medicine, Liverpool L3 5QA, United Kingdom

Stephen A. Ward - Department of Tropical Disease Biology, Liverpool School of Tropical Medicine, Liverpool L3 5QA, United Kingdom

Mark J. Taylor - Department of Tropical Disease Biology, Liverpool School of Tropical Medicine, Liverpool L3 SQA, United Kingdom

Complete contact information is available at:

https://pubs.acs.org/10.1021/acsmedchemlett.1c00216

\section{Author Contributions}

The manuscript was written through contributions of all authors. W.D.H., M.J.T., S.A.W., and P.M.O. designed research; P.McG. performed synthesis; P.J.H.W., M.C.W., and S.K. performed in silico and in vitro DMPK and safety studies; A.C., R.H.C., D.A.C., and K.L.J. performed parasitology studies; W.D.H., N.G.B. G.L.N., L.F., K.L.J., and P.M.O. analyzed data.

\section{Notes}

The authors declare no competing financial interest.

\section{ACKNOWLEDGMENTS}

The A.WOL consortium is supported by grants from the Bill \& Melinda Gates Foundation awarded to the Liverpool School of Tropical Medicine. This work was also supported by a GHIT grant awarded to M.J.T., S.A.W., and P.O.N. Experiments, including synthesis and animal PK studies, performed at Wuxi AppTec, led by Nigel Liverton and Chengkun Huang, were supported by the Bill \& Melinda Gates Foundation financially. We would also like to thank Mark Timms in AstraZeneca Compound Management in Alderley Park for the logistics of arranging the in vitro DMPK and safety studies.

\section{ABBREVIATIONS}

LF, lymphatic filariasis; DEC, diethylcarbamazine; HTS, highthroughput screening; DMPK, drug metabolism pharmacokinetics; DOX, doxycycline; PD, Pharmacodynamics; PK, pharmacokinetics; SAR, structure-activity relationships; B.malayi, Brugia malayi; mf, microfilariae; SCID, severe combined immunodeficient 


\section{REFERENCES}

(1) Taylor, M. J.; Hoerauf, A.; Bockarie, M. Lymphatic filariasis and onchocerciasis. Lancet 2010, 376 (9747), 1175-85.

(2) Weil, G. J.; Jacobson, J. A.; King, J. D. A triple-drug treatment regimen to accelerate elimination of lymphatic filariasis: From conception to delivery. International Health 2020, 13 (Supplement_1), S60-S64.

(3) Bockarie, M. J.; Deb, R. M. Elimination of lymphatic filariasis: do we have the drugs to complete the job? Curr. Opin. Infect. Dis. 2010, 23 (6), 617-20.

(4) Mackenzie, C. D.; Homeida, M. M.; Hopkins, A. D.; Lawrence, J. C. Elimination of onchocerciasis from Africa: possible? Trends Parasitol. 2012, 28 (1), 16-22.

(5) Boussinesq, M.; Fobi, G.; Kuesel, A. C. Alternative treatment strategies to accelerate the elimination of onchocerciasis. Int. Health 2018, 10 (suppl_1), i40-i48.

(6) Johnston, K. L.; Ford, L.; Taylor, M. J. Overcoming the challenges of drug discovery for neglected tropical diseases: the A.WOL experience. J. Biomol. Screening 2014, 19 (3), 335-43.

(7) Taylor, M. J.; Bandi, C.; Hoerauf, A. Wolbachia bacterial endosymbionts of filarial nematodes. Adv. Parasitol. 2005, 60, 24584.

(8) Saint Andre, A.; Blackwell, N. M.; Hall, L. R.; Hoerauf, A.; Brattig, N. W.; Volkmann, L.; Taylor, M. J.; Ford, L.; Hise, A. G.; Lass, J. H.; Diaconu, E.; Pearlman, E. The role of endosymbiotic Wolbachia bacteria in the pathogenesis of river blindness. Science 2002, 295 (5561), 1892-5.

(9) Taylor, M. J.; Makunde, W. H.; McGarry, H. F.; Turner, J. D.; Mand, S.; Hoerauf, A. Macrofilaricidal activity after doxycycline treatment of Wuchereria bancrofti: a double-blind, randomised placebo-controlled trial. Lancet 2005, 365 (9477), 2116-21.

(10) Hoerauf, A.; Specht, S.; Buttner, M.; Pfarr, K.; Mand, S.; Fimmers, R.; Marfo-Debrekyei, Y.; Konadu, P.; Debrah, A. Y.; Bandi, C.; Brattig, N.; Albers, A.; Larbi, J.; Batsa, L.; Taylor, M. J.; Adjei, O.; Buttner, D. W. Wolbachia endobacteria depletion by doxycycline as antifilarial therapy has macrofilaricidal activity in onchocerciasis: a randomized placebo-controlled study. Med. Microbiol. Immunol. 2008, 197 (3), 295-311.

(11) Turner, J. D.; Tendongfor, N.; Esum, M.; Johnston, K. L.; Langley, R. S.; Ford, L.; Faragher, B.; Specht, S.; Mand, S.; Hoerauf, A.; Enyong, P.; Wanji, S.; Taylor, M. J. Macrofilaricidal activity after doxycycline only treatment of Onchocerca volvulus in an area of Loa loa co-endemicity: a randomized controlled trial. PLoS Neglected Trop. Dis. 2010, 4 (4), e660.

(12) Ali, S.; Heathcote, D. A.; Kroll, S. H.; Jogalekar, A. S.; Scheiper, B.; Patel, H.; Brackow, J.; Siwicka, A.; Fuchter, M. J.; Periyasamy, M.; Tolhurst, R. S.; Kanneganti, S. K.; Snyder, J. P.; Liotta, D. C.; Aboagye, E. O.; Barrett, A. G.; Coombes, R. C. The development of a selective cyclin-dependent kinase inhibitor that shows antitumor activity. Cancer Res. 2009, 69 (15), 6208-15.

(13) Patel, H.; Periyasamy, M.; Sava, G. P.; Bondke, A.; Slafer, B. W.; Kroll, S. H. B.; Barbazanges, M.; Starkey, R.; Ottaviani, S.; Harrod, A.; Aboagye, E. O.; Buluwela, L.; Fuchter, M. J.; Barrett, A. G. M.; Coombes, R. C.; Ali, S. ICEC0942, an Orally Bioavailable Selective Inhibitor of CDK7 for Cancer Treatment. Mol. Cancer Ther. 2018, 17 (6), 1156-1166.

(14) Soares de Melo, C.; Feng, T. S.; van der Westhuyzen, R.; Gessner, R. K.; Street, L. J.; Morgans, G. L.; Warner, D. F.; Moosa, A.; Naran, K.; Lawrence, N.; Boshoff, H. I.; Barry, C. E., 3rd; Harris, C. J.; Gordon, R.; Chibale, K. Aminopyrazolo[1,5-a]pyrimidines as potential inhibitors of Mycobacterium tuberculosis: Structure activity relationships and ADME characterization. Bioorg. Med. Chem. 2015, 23 (22), 7240-50.

(15) Azeredo, L.; Coutinho, J. P.; Jabor, V. A. P.; Feliciano, P. R.; Nonato, M. C.; Kaiser, C. R.; Menezes, C. M. S.; Hammes, A. S. O.; Caffarena, E. R.; Hoelz, L. V. B.; de Souza, N. B.; Pereira, G. A. N.; Ceravolo, I. P.; Krettli, A. U.; Boechat, N. Evaluation of 7arylaminopyrazolo[1,5-a $]$ pyrimidines as anti-Plasmodium falciparum, antimalarial, and Pf-dihydroorotate dehydrogenase inhibitors. Eur. J. Med. Chem. 2017, 126, 72-83.

(16) Hwang, J. Y.; Windisch, M. P.; Jo, S.; Kim, K.; Kong, S.; Kim, H. C.; Kim, S.; Kim, H.; Lee, M. E.; Kim, Y.; Choi, J.; Park, D. S.; Park, E.; Kwon, J.; Nam, J.; Ahn, S.; Cechetto, J.; Kim, J.; Liuzzi, M.; No, Z.; Lee, J. Discovery and characterization of a novel 7aminopyrazolo[1,5-a]pyrimidine analog as a potent hepatitis $\mathrm{C}$ virus inhibitor. Bioorg. Med. Chem. Lett. 2012, 22 (24), 7297-301.

(17) Wustrow, D. J.; Capiris, T.; Rubin, R.; Knobelsdorf, J. A.; Akunne, H.; Davis, M. D.; MacKenzie, R.; Pugsley, T. A.; Zoski, K. T.; Heffner, T. G.; Wise, L. D. Pyrazolo[1,5-a $]$ pyrimidine CRF-1 receptor antagonists. Bioorg. Med. Chem. Lett. 1998, 8 (16), 2067-70.

(18) Clare, R. H.; Cook, D. A.; Johnston, K. L.; Ford, L.; Ward, S. A.; Taylor, M. J. Development and validation of a high-throughput anti-Wolbachia whole-cell screen: a route to macrofilaricidal drugs against onchocerciasis and lymphatic filariasis. J. Biomol. Screening 2015, 20 (1), 64-9.

(19) Halliday, A.; Guimaraes, A. F.; Tyrer, H. E.; Metuge, H. M.; Patrick, C. N.; Arnaud, K. O.; Kwenti, T. D.; Forsbrook, G.; Steven, A.; Cook, D.; Enyong, P.; Wanji, S.; Taylor, M. J.; Turner, J. D. A murine macrofilaricide pre-clinical screening model for onchocerciasis and lymphatic filariasis. Parasites Vectors 2014, 7, 472.

(20) Dillard, L. W.; Dwyer, M. P.; Girijavallabhan, V. M.; Guzi, T. J.; He, Z. M.; James, R. A.; Park, H.; Paruch, K., Tran, V. D. Pyrazolopyrimidines as Cyclin Dependent Kinase Inhibitors. Patent WO2004022560 A1, 2004.

(21) Hong, W. D.; Benayoud, F.; Nixon, G. L.; Ford, L.; Johnston, K. L.; Clare, R. H.; Cassidy, A.; Cook, D. A. N.; Siu, A.; Shiotani, M.; Webborn, P. J. H.; Kavanagh, S.; Aljayyoussi, G.; Murphy, E.; Steven, A.; Archer, J.; Struever, D.; Frohberger, S. J.; Ehrens, A.; Hubner, M. P.; Hoerauf, A.; Roberts, A. P.; Hubbard, A. T. M.; Tate, E. W.; Serwa, R. A.; Leung, S. C.; Qie, L.; Berry, N. G.; Gusovsky, F.; Hemingway, J.; Turner, J. D.; Taylor, M. J.; Ward, S. A.; O’Neill, P. M. AWZ1066S, a highly specific anti-Wolbachia drug candidate for a short-course treatment of filariasis. Proc. Natl. Acad. Sci. U. S. A. 2019, 116 (4), 1414-1419.

(22) Clare, R. H.; Bardelle, C.; Harper, P.; Hong, W. D.; Borjesson, U.; Johnston, K. L.; Collier, M.; Myhill, L.; Cassidy, A.; Plant, D.; Plant, H.; Clark, R.; Cook, D. A. N.; Steven, A.; Archer, J.; McGillan, P.; Charoensutthivarakul, S.; Bibby, J.; Sharma, R.; Nixon, G. L.; Slatko, B. E.; Cantin, L.; Wu, B.; Turner, J.; Ford, L.; Rich, K.; Wigglesworth, M.; Berry, N. G.; O’Neill, P. M.; Taylor, M. J.; Ward, S. A. Industrial scale high-throughput screening delivers multiple fast acting macrofilaricides. Nat. Commun. 2019, 10 (1), 11.

(23) hERG inhibition, $\mathrm{IC}_{50}=24.9 \mu \mathrm{M}(\mathbf{1 5 f})$ and $>33.3 \mu \mathrm{M}(\mathbf{1 5 j})$; cyctotoxicity (against THP-1), $\mathrm{IC}_{50}>50 \mu \mathrm{M}(\mathbf{1 5 f}$ and $\mathbf{1 5 j})$. 